\title{
PENYUSUNAN KEBIJAKAN UNTUK MENDORONG MOTIVASI GENERASI MUDA BERWIRAUSAHA DI BIDANG PERTANIAN
}

\author{
Mariyah $^{1}$, Rita Mariati ${ }^{1}$, Agung Enggal Nugroho ${ }^{1}$ \\ 'Jurusan Agribisnis Fakultas Pertanian Universitas Mulawarman \\ E-mail: ademariyah81@gmail.com; rita.mariati@yahoo.com; agungenggal@faperta.unmul.ac.id
}

\begin{abstract}
ABSTRAK
Regenerasi petani dengan penguatan jiwa kewirausahaan dibutuhkan untuk menghadapi tantangan usaha yang semakin kompetitif. Penurunan jumlah generasi muda yang masuk ke dunia pertanian perlu diantisipasi melalui pendidikan formal bidang pertanian. Penelitian ini bertujuan mendeskripsikan minat generasi muda ke bidang pertanian dan faktor-faktor yang memengaruhi motivasinya berwirausaha dibidang pertanian. Penelitian dilakukan melalui survei terhadap mahasiswa baru Jurusan Agribisnis Fakultas Pertanian Universitas Mulawarman dengan pertimbangan salah satu capaian pembelajaran yang direncanakan adalah wirausaha pertanian. Hasil penelitian menunjukkan minat ke bidang pertanian masih menunjukkan peningkatan berdasarkan trend jumlah mahasiswa, motivasi berasal dari keinginan sendiri, dan sebagian besar merupakan pilihan pertama program studi, serta memiliki keinginan untuk berwirausaha dibidang pertanian. Faktor yang dan memengaruhi motivasinya adalah pendidikan sebelumnya, latar belakang orangtua (jenis pekerjaan, usaha, kepemilikan lahan), serta pengalaman ke lokasi pertanian. Implikasi penelitian ini adalah perlunya penetapan prioritas pendidikan wirausaha pertanian, dukungan, dan komitmen dalam pendampingan dan pembinaan generasi muda agar mampu berwirausaha.
\end{abstract}

Kata kunci: Motivasi, Pendidikan, Pertanian, Petani, Regenerasi, Wirausaha

\section{PERNYATAAN KUNCI}

Sumberdaya manusia merupakan faktor kunci dalam pengelolaan usaha pertanian. Kemampuan manajerial sangat diperlukan agar usaha yang dijalankan memberikan keuntungan yang layak. Regenerasi petani berjalan lamban dan minat generasi muda untuk berperan dibidang pertanian semakin rendah. Peluang usaha, kreativitas, dan inovasi berbasis revolusi 4.0 melalui pendidikan formal diharapkan mampu menarik kembali generasi muda untuk berwirausaha di bidang pertanian.

\section{REKOMENDASI KEBIJAKAN}

Wirausaha pertanian melalui pendidikan formal pertanian di tingkat pendidikan tinggi dapat ditumbuh kembangkan dan terbentuk melalui (1) upaya penetapan pendidikan wirausaha pertanian sebagai sebuah prioritas dalam 
proses pembelajaran, (2) memberikan dukungan secara moril dan materi terhadap pengembangan jiwa kewirausahaan bagi dosen dan mahasiswa serta (3) komitmen yang kuat untuk mengkolaborasikan dunia pendidikan dengan dunia usaha.

\section{PENDAHULUAN}

Kalimantan Timur merupakan salah satu provinsi yang berada di Pulau Kalimantan dengan suku dan budaya yang beragam serta memiliki rentang geografis yang sangat luas. Sektor pertambangan dan penggalian menjadi sektor dominan yang berkontribusi terhadap perekonomian daerah yaitu sebesar 46,35\% (Badan Pusat Statistik Kalimantan Timur, 2020). Namun, sektor ini tidak bisa menjadi tumpuan karena merupakan sumberdaya yang tidak dapat diperbaharui (Non-renewable resources). Oleh sebab itu, sektor pertanian sebagai sektor kedua yang berkontribusi terhadap perekonomian daerah perlu menjadi fokus untuk terus dikembangkan. Kontribusi sektor pertanian sebesar 7,88\% terhadap perekonomian Kalimantan Timur (Badan Pusat Statistik Kalimantan Timur, 2020).

$$
\text { Anandita dan Patria (2016) }
$$
menyatakan bahwa sektor pertanian dihadapkan pada penurunan jumlah petani, penurunan kepemilikan lahan, dan rendahnya regenerasi petani. Kebanyakan dari anak-anak petani memilih untuk bekerja diluar sektor pertanian. Regenerasi petani menjadi faktor kunci agar pertanian tidak stagnan dan mengalami penurunan (Anwarudin, et al. 2018). Beberapa faktor yang menjadi penentu regenerasi petani adalah karakteristik generasi muda, dukungan pemerintah, keluarga, dan masyarakat, dukungan pasar, peran penyuluh pertanian, motivasi generasi muda, serta partisipasi mereka dalam pertanian.

Universitas Mulawarman berdiri sejak tahun 1962. Fakultas pertanian menjadi salah satu institusi pendidikan formal yang dibuka untuk memberikan dukungan terhadap pembangunan pertanian. Bukan saja berperan dalam pendidikan dibidang pertanian tetapi institusi ini berupaya untuk mencetak generasi muda untuk dapat berwirausaha di bidang pertanian.

Wirausaha pertanian relatif berbeda dengan wirausaha pada umumnya. Wirausaha pertanian menurut Lans, Seuneke, et al. (2013) terdiri atas orientasi wirausaha, gaya dan peran wirausaha, wirausaha yang baru, pemula, dan ahli, serta fasilitas pendukung wirausaha. Orientasi wirausaha merupakan kesediaan petani untuk berinovasi memenuhi permintaan pasar, mengambil risiko untuk mencoba produk baru dan ketidakpastian, lebih proaktif mencari peluang pasar. Tiga elemen kunci kewirausahaan adalah inovasi, pengambilan risiko, dan proaktif. Pemilik usaha pertanian dapat berperan sebagai seorang wirausaha, berperan dalam 
manajerial, dan berperan dalam teknis usahanya. Wirausaha pertanian (agricultural entrepreneurship) memiliki potensi besar untuk digali dan dikembangkan (Martinho, 2020).

Khonitan dan Utami (2018) pada penelitian menunjukkan bahwa faktorfaktor yang berpengaruh pada generasi muda untuk masuk di bidang pertanian adalah asal sekolah, orientasi pekerjaan, dukungan pengajar, dan dukungan orangtua. Insani, Setiawan, \& Rasiska (2018) menyatakan bahwa faktor yang dapat meningkatkan partisipasi petani muda adalah motivasi, inovasi, dan lingkungan. Hasil penelitian Nazaruddin (2017) bahwa minat generasi muda dipengaruhi secara langsung oleh lingkungan sosial melalui dinamika kelompok. Menurut Šimpachová (2018), motivasi generasi muda untuk masuk ke pertanian dan berwirausaha dihadapkan pada kendala kepemilikan lahan dan akses terhadap pembiayaan (credit). Kepemilikan lahan pertanian perlu dialihkan ke generasi berikutnya, diperlukan dukungan pembiayaan untuk aset yang berwujud (tangible asset) dan aset yang tidak berwujud (intangible asset) berupa transfer pengetahuan dan pembelajaran).

Tulisan ini bertujuan memberikan gambaran mengenai motivasi generasi muda masuk ke pertanian melalui pendidikan formal dan beberapa faktor yang melatarbelakangi keinginan mereka untuk berwirausaha dengan studi kasus pada mahasiswa baru Jurusan Agribisnis Fakultas Pertanian Universitas Mulawarman.

\section{SITUASI TERKINI}

Penduduk berusia 15 tahun keatas merupakan penduduk dengan usia produktif yang diharapkan sebagai penggerak utama dalam kegiatan ekonomi. Aktivitas mereka akan memberikan kontribusi terhadap pendapatan rumahtangga. Besarnya pendapatan menjadi cerminan tingkat kesejahteraan. Penduduk berusia 15 tahun ke atas di Kalimantan Timur berdasarkan data Survei Angkatan Kerja Nasional Agustus 2020 oleh Badan Pusat Statistik berjumlah 2.732.343 jiwa. Angkatan kerja sebesar 66,44 \% dan bukan angkatan kerja sebesar 33,56 \%.

Tabel 1. Jumlah Angkatan Kerja dan Bukan Angkatan Kerja di Kalimantan Timur Agustus 2020

\begin{tabular}{lrrr}
\hline $\begin{array}{c}\text { Kabupaten/ } \\
\text { Kota }\end{array}$ & $\begin{array}{c}\text { Angkatan } \\
\text { Kerja }\end{array}$ & $\begin{array}{c}\text { Bukan } \\
\text { Angkata } \\
\text { n Kerja }\end{array}$ & $\begin{array}{c}\text { Gabunga } \\
\text { n }\end{array}$ \\
\hline Paser & 137,737 & 69,611 & 207,348 \\
Kutai Barat & 72,552 & 35,271 & 107,823 \\
Kutai & 377,924 & 194,080 & 572,004 \\
Kartanegara & & & \\
Kutai Timur & 188,148 & 83,613 & 271,761 \\
Berau & 110,963 & 54,384 & 165,347 \\
Penajam & 74,976 & 41,357 & 116,333 \\
Paser Utara & & & 18,715 \\
Mahakam & 13,203 & 5,512 & \\
Ulu & & & 490,931 \\
Balikpapan & 324,635 & 166,296 & 654,968 \\
Samarinda & 428,353 & 226,615 & 67,113 \\
Bontang & 86,891 & 40,222 & 1273 \\
Jumlah & $1,815,38$ & 916,961 & $2,732,34$ \\
& 2 & & 3 \\
\hline
\end{tabular}

Sumber: Widhaningrat (2010). 
Penduduk yang bekerja di bidang pertanian, kehutanan, dan pertanian pada tahun 2019 sebesar 19 persen.

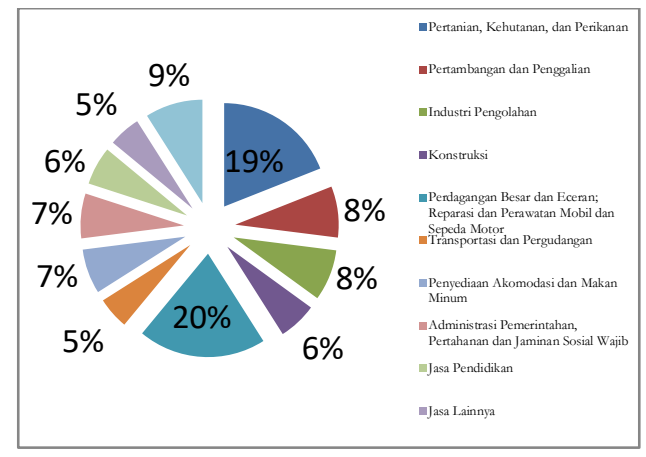

Grafik 1. Persentase Penduduk Berumur 15 Tahun Ke Atas yang Bekerja Menurut Lapangan Pekerjaan Utama di Kalimantan Timur, Agustus 2019

Status pekerjaan utama penduduk berusia 15 tahun ke atas sebesar 20,99 persen berusaha sendiri, pekerja bebas di sektor pertanian $7,51 \%$, berusaha dibantu buruh tidak tetap/tidak dibayar/pekerja keluarga $8,73 \%$, berusaha dibantu buruh tetap dan dibayar 4,30\%, buruh/ karyawan/pegawai 54,87\%.

Berdasarkan data ini maka dapat diketahui bahwa penduduk di Kalimantan Timur yang berusaha sendiri berda pada urutan kedua dari jumlah penduduk yang bekerja. Berusaha sendiri yang dimaksud adalah mereka yang bekerja atas resiko sendiri tanpa bantuan orang lain (Widhaningrat, 2010). Berdasarkan teoritis, mereka ini tergolong wirausaha dilihat dari ciri wirausaha yaitu memiliki kemampuan dalam pengambilan resiko. Wirausaha adalah pionir dalam bisnis, inovator, penanggung resiko, mempunyai visi ke depan, memiliki keunggulan dalam berprestasi di bidang usaha.

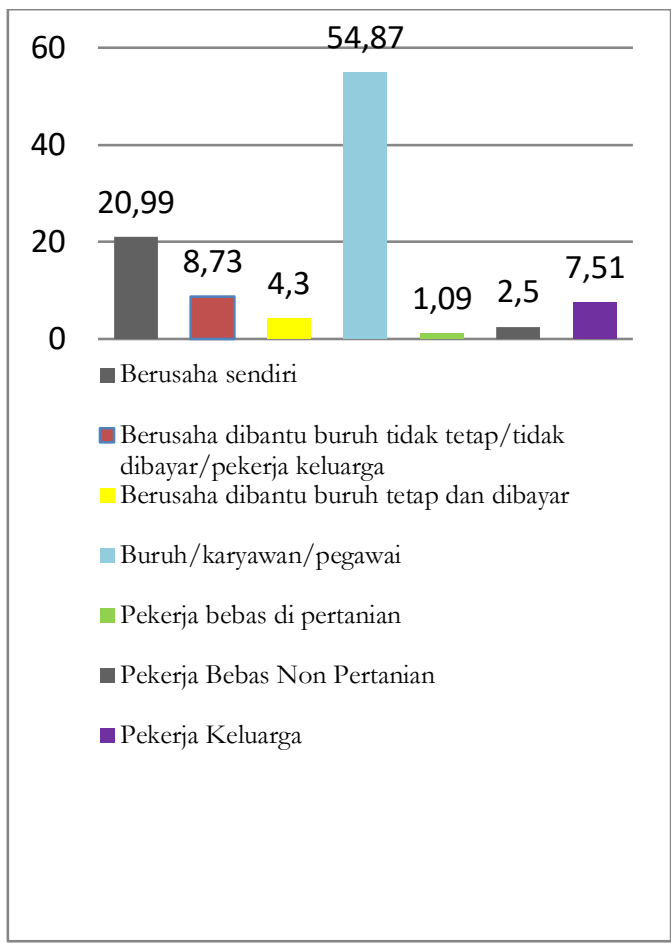

Grafik 2. Persentase Penduduk Berumur 15 tahun keatas yang Bekerja Menurut Status Pekerjaan Utama dan Jenis Kelamin di Kalimantan Timur, Agustus 2019

Upaya menggerakkan jiwa wirausaha menjadi sangat penting. Fakultas Pertanian menjadi salah satu lembaga pendidikan tinggi yang mengarahkan mahasiswa dan alumninya untuk dapat bergerak di bidang pertanian.

Jika dibandingkan dengan fakultas lain yang berada di Universitas Mulawarman maka mahasiswa yang bergerak di bidang pertanian berjumlah 4.686 mahasiswa dari 31.749 orang atau hanya $14,76 \%$ dari jumlah total mahasiswa (Mulawarman, 2020). Pertanian yang dimaksud meliputi Fakultas Pertanian sebanyak 1.786 orang, Fakultas Kehutanan sebanyak 1.327 orang, dan 
Fakultas Perikanan dan Ilmu Kelautan sebanyak 1.573 orang.

Tabel 2. Jumlah Mahasiswa Universitas Mulawarman Tahun 2020

\begin{tabular}{llr}
\hline No & Fakultas & Jumlah \\
\hline 1 & Fakultas Ekonomi dan Bisnis & 4.727 \\
2 & Fakultas Ilmu Politik dan Ilmu & 4.916 \\
& Sosial & \\
3 & Fakultas Pertanian & 1.786 \\
4 & Fakultas Kehutanan & 1.327 \\
5 & Fakultas Keguruan dan Ilmu & 7.558 \\
& Pendidikan & \\
6 & Fakultas Perikanan dan Ilmu & 1.573 \\
& Kelautan & \\
7 & FMIPA & 1.112 \\
8 & Fakultas Hukum & 1.412 \\
9 & Fakultas Teknik & 835 \\
10 & Fakultas Kedokteran & 658 \\
11 & Fakultas Kesehatan Masyarakat & 1.131 \\
12 & Fakultas Farmasi & 1.255 \\
13 & Fakultas Ilmu Budaya & \\
\hline
\end{tabular}

Sumber: Mulawarman (2020)

\section{ANALISIS DAN ALTERNATIF SOLUSI/PENANGANAN}

Minat generasi muda di bidang pertanian mengalami peningkatan ditunjukkan berdasarkan trend jumlah mahasiswa di Fakultas Pertanian:

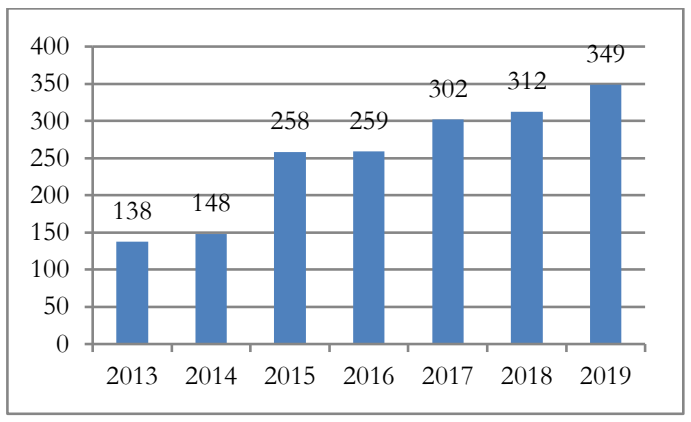

Sumber: Mulawarman (2020)

Grafik 3. Perkembangan Jumlah

Mahasiswa Fakultas Pertanian

Berdasarkan survei terhadap mahasiswa baru program studi agribisnis tahun 2020 sebanyak 75 orang dapat diperoleh gambaran beberapa hal sebagai berikut:

\section{Asal Sekolah Lanjutan Tingkat Atas}

Sebagian besar mahasiswa baru berasal dari SMA sebanyak 65 orang $(86,67 \%)$ dan hanya 10 orang $(13,33 \%)$ dari SMK. Asal sekolah menunjukkan sebagian besar yang masuk ke fakultas pertanian belum memiliki dasar keilmuan bidang pertanian. Mahasiswa yang berasal dari SMK pertanian hanya 4 orang dan lainnya berasal dari SMK jurusan di luar pertanian.

\section{Latar Belakang Orangtua}

a. Pekerjaan

Orangtua menjadi lingkup masyarakat terkecil dalam keluarga yang mampu memberikan dorongan dan dukungan agar anaknya bisa terjun ke bidang pertanian. Jika dilihat dari pekerjaan, maka sebagian besar orangtua mereka adalah petani, seorang wirausaha, dan karyawan swasta.

Tabel 4. Jenis Pekerjaan Orangtua

\begin{tabular}{lrr}
\hline $\begin{array}{c}\text { Jenis } \\
\text { Pekerjaan }\end{array}$ & $\begin{array}{r}\text { Jumlah } \\
\text { (Orang) }\end{array}$ & $\begin{array}{c}\text { Persentase } \\
\mathbf{( \% )}\end{array}$ \\
\hline Petani & 18 & 24,00 \\
Wirausaha & 12 & 16,00 \\
PNS & 14 & 18,67 \\
TNI/Polri & 1 & 1,33 \\
Karyawan & & \\
Swasta & 18 & 24,00 \\
Lainnya & 13 & 17,33 \\
\hline Sumber: Data primer (diolah), 2020.
\end{tabular}

b. Kepemilikan Lahan

Berdasarkan kepemilikan lahan, orangtua mahasiswa baru yang memiliki lahan hanya sebanyak 29 orang $(38,67 \%)$ dan yang tidak memiliki lahan sebanyak 46 orang $(61,33 \%)$. 
Lahan merupakan faktor produksi utama di bidang pertanian. Banyaknya orangtua yang tidak memiliki lahan memberikan gambaran tidak terjadinya perpindahan kepemilikan lahan kepada generasi selanjutnya. Namun, perlu diberi penekanan bahwa usaha pertanian saat ini tidak hanya pada aspek budidaya pertanian pada lahan tertentu. Usaha bidang pertanian dapat ditekuni dari hulu (on-farm) hingga hilir (off-farm). Inovasi teknologi budidaya memberikan kemajuan teknis budidaya dan memberi banyak pilihan bagi kita untuk berusaha di bidang pertanian dengan berbagai media tanam dan peralatan budidaya alternatif.

c. Usaha orangtua di bidang pertanian

Berdasarkan bidang usaha orang tua dibidang pertanian, hanya sebanyak 27 orang $(36,00 \%)$ yang memiliki usaha dibidang pertanian dan yang tidak berusaha dibidang pertanian sebanyak 48 orang $(64,00 \%)$.

Anak akan memperoleh pengalaman dan pengetahuan dari terjun langsung dalam usaha orangtuanya. Rendahnya orangtua yang berusaha dibidang pertanian menjadi kendala dalam memperkenalkan pertanian kepada generasi muda.

\section{Jenis Kelamin}

Berdasarkan jenis kelamin, peminat untuk Program Studi Agribisnis sebagian besar adalah perempuan yaitu 47 orang $(62,67 \%)$ dan laki-laki sebanyak 28 orang $(37,33 \%)$. Jenis kelamin tidak menjadi hambatan untuk berwirausaha di bidang pertanian.

\section{Pengalaman Jalan ke Lokasi Usaha Pertanian}

Sebagian besar mahasiswa sering $(25,33 \%)$ dan pernah (52,00\%) berkunjung ke lokasi usaha pertanian. Sebagian besar mahasiswa berasal dari kabupaten/kota yang merupakan sentra pertanian di Kalimantan Timur, antara lain Kabupaten Kutai Kartanegara, Kutai Timur, Paser, Penajam Paser utara, dan Berau serta terdapat beberapa mahasiswa (9,33\%) yang berasal dari Sulawesi Selatan dan Sumatera Utara yang juga merupakan sentra pertanian. Hanya sekitar 28\% mahasiswa yang berasal dari kota yaitu Kota Samarinda, Balikpapan, dan Bontang. Namun, kotakota ini juga terdapat daerah-daerah pertanian.

Pengalaman ini memberikan gambaran langsung kepada mereka terhadap apa yang dilakukan di pertanian dan peluang apa yang dapat mereka ambil. Hobi generasi muda yang cenderung suka berpetualang, berkumpul, dan menikmati perjalanan serta wisata kuliner menjadi modal tersendiri guna mendorong generasi muda memiliki jiwa wirausaha. 
Tabel 5. Pengalaman ke Lokasi Pertanian

\begin{tabular}{lrr}
\hline Pengalaman & $\begin{array}{c}\text { Jumlah } \\
\text { (orang) }\end{array}$ & $\begin{array}{c}\text { Persentase } \\
\text { (\%) }\end{array}$ \\
\hline Sering & 19 & 25,33 \\
Pernah & 39 & 52,00 \\
Tidak Pernah & 17 & 22,67 \\
\hline
\end{tabular}

Sumber: Data primer (diolah), 2020.

5. Motivasi ke pertanian dan Berwirausaha

Berdasarkan survei, keinginan sendiri $(82,67 \%)$ menjadi motivasi terbesar untuk masuk pertanian $\mathrm{Hal}$ ini didukung dengan data berdasarkan pilihan program studi, maka sebanyak 49 orang $(65,33 \%)$ merupakan pilihan pertama, 14 orang $(18,67 \%)$ pilihan kedua, dan hanya 3 orang (4\%) yang merupakan pilihan ketiga.

Rendahnya mahasiswa yang masuk dari rekomendasi seseorang $(12,00 \%)$ perlu mendapat perhatian. Artinya, perlu keperdulian civitas akademika untuk mengajak siswa lulusan SLTA/SMK untuk mau masuk dan belajar tentang pertanian. Upaya ini perlu dilakukan secara terprogram dan terencana melalui institusi maupun secara personal.

Tabel 6. Motivasi Mahasiswa

\begin{tabular}{lrr}
\hline \multicolumn{1}{c}{ Motivasi } & $\begin{array}{c}\text { Jumlah } \\
\text { (Orang) }\end{array}$ & $\begin{array}{c}\text { Persentase } \\
(\mathbf{\%})\end{array}$ \\
\hline Keinginan Sendiri & 62 & 82,67 \\
Diminta Orangtua & 6 & 8,00 \\
Melanjutkan & & \\
Pendidikan & & \\
Sebelumnya & 4 & 5,33 \\
Ikut-ikutan Teman & 1 & 1,33 \\
Rekomendasi & & \\
Seseorang & 9 & 12,00 \\
Lainnya & 4 & 5,33 \\
\hline Sumber: Data primer (diolah), 2020.
\end{tabular}

\section{Keinginan Untuk Berwirausaha}

Berdasarkan keinginan untuk berwirausaha, sebanyak 67 orang $(89,33 \%)$ berkeinginan untuk menjadi wirausaha dan hanya 8 orang $(10,67 \%)$ yang tidak berkeinginan untuk berwirausaha.

Berdasarkan hal tersebut, terdapat beberapa alternatif yang dapat diupayakan oleh Fakultas Pertanian guna membentuk mahasiswa yang memiliki jiwa wirausaha sebagai berikut:

1. Mensosialisasikan pendidikan bidang pertanian sejak jenjang sekolah menengah atas

Fakultas Pertanian dapat melakukan sosialisasi secara langsung dengan melakukan kunjungan ke sekolah-sekolah dan melakukan diskusi tentang pertanian, serta mengundang siswa-siswa untuk berkunjung ke Fakultas Pertanian. Promosi tidak langsung dengan memanfaatkan media sosial, brosur, dan pameran.

2. Menyusun kurikulum berbasis kompetensi pertanian sesuai capaian lulusan yang diinginkan

Setiap mata kuliah mulai diarahkan ke terbentuknya jiwa kewirausahaan baik melalui pembelajaran di kelas maupun praktikum di lapangan. Pembelajaran dapat dilakukan dengan mengundang dosen tamu dari kalangan praktisi 
usaha. Praktikum dilakukan dengan membawa mahasiswa ke unit-unit usaha masyarakat dan magang/praktik kerja lapangan dengan dukungan pendanaan dan pendampingan.

3. Membentuk komunitas pertanian dan wirausaha.

Komunitas pertanian dapat dibentuk dari hulu hingga hilir. Kegiatan dapat berupa diskusi maupun praktik usaha. Beberapa tahapan kegiatan di pertanian yang dapat menjadi peluang usaha adalah:

a. Tahapan pengolahan tanah dari penyediaan peralatan pengolahan, uji tanah, penyediaan bahan-bahan untuk perbaikan tanah.

b. Tahapan Perbenihan: konsultasi perbenihan, penyediaan benih, distribusi benih.

c. Tahapan Pengairan: pembuatan rencana irigasi, penyediaan peralatan, penyediaan tenaga pembuat fasilitas irigasi.

d. Tahapan Pengendalian OPT: Konsultasi OPT, penyediaan obatobatan dan peralatannya.

e. Tahapan Pemupukan: konsultasi pemupukan, penyediaan pupuk.

f. Tahapan Panen/Pasca Panen: penyediaan peralatan panen, fasilitas penjemuran, dan pengolahan. g. Tahapan Pemasaran: pedagang perantara dan jasa transportasi.

4. Memperkenalkan pertanian melalui eduagrowisata

Generasi muda senang dengan sesuatu yang dapat menjadi trending, maka dapat dibuat suatu lokasi pertanian percontohan sebagai destinasi wisata. Selain memberikan pengalaman juga menjadi peluang bisnis ikutan terutama pada pengolahan hasil pertanian menjadi makanan atau masakan tertentu.

5. Penguatan kewirausahaan dosen dan mahasiswa melalui bimbingan teknis dan pelatihan

Dosen dan mahasiswa diikutsertakan dalam bimbingan teknis dan pelatihan kewirausahaan dalam jangka waktu tertentu yang diselenggarakan oleh pihak terkait seperti Dinas Perindustrian dan Perdagangan, LPOM, Dinas Pertanian, dan Balai-balai Penelitian dan Pengembangan.

6. Memperbanyak intensitas kegiatan dan kompetisi kewirausahaan bagi mahasiswa

Mahasiswa difasilitasi untuk mengikuti program kreativitas mahasiswa serta memasukkan berbagai praktik kewirausahaan dalam setiap materi kuliah yang berkesesuaian. 
7. Menyediakan fasilitas sosialisasi agricultural entrepreneurship dengan konten menarik melalui media sosial Menumbuhkembangkan jiwa wirausaha juga dapat dilakukan dengan membuat konten promosi pertanian yang berisikan profil pengusaha pertanian, kegiatan pertanian, dan produk pertanian baik dalam bentuk segar maupun olahan. Pemanfaatan media sosial yang dekat dan selalu dimanfaatkan oleh generasi muda dapat menjadi sarana menumbuhkan kecintaan pada dunia pertanian.

\section{REFERENSI}

Anandita, D.A., Patria, K.Z. 2016. Agriculture Challenges: Decline of Farmers and Farmland Study from Indonesian Family Life Survey, 16(1).

Anwarudin, O., Satria, A., Fatchiya, A. 2018. A Review on Farmer Regeneration and Its Determining Factors in Indonesia. International Journal of Progressive Sciences and Technologies, 10(2), 218-230.

Badan Pusat Statistik Kalimantan Timur. 2020. Provinsi Kalimantan Timur Dalam Angka 2019.

Insani, F.R., Setiawan, I., Rasiska, S. 2018. Determinan Partisipasi Dan Peran Petani Muda Dalam Pengembangan Pertanian Ramah Lingkungan Di Desa Cisondari, Kecamatan Ciwidey, Kabupaten Bandung, Jawa Barat. MIMBAR AGRIBISNIS: Jurnal Pemikiran Masyarakat Ilmiah
Berwawasan Agribisnis, 4(2), 153. https://doi.org/10.25157/ma.v4i2. 1133

Khonitan, D., Utami, B.N. 2018. Motivasi Generasi Muda Dalam Menyongsong Revolusi Industri 4.0 Melalui Pendidikan Bidang Pertanian Di Sekolah Tinggi Penyuluhan Pertanian Malang. Jurnal Sains Psikologi, 8(1), 162170.

https://doi.org/10.17977/um023v 8i12019p162

Lans, T., Seuneke, P., Wageningen, A.H., Klerkx, L. 2013. Encyclopedia of Creativity, Invention, Innovation and Entrepreneurship. Encyclopedia of Creativity, Invention, Innovation and Entrepreneurship, (March 2014). https://doi.org/10.1007/978-14614-3858-8

Martinho, V.J.P.D. 2020. Agricultural entrepreneurship in the european union: Contributions for a sustainable development. Applied Sciences (Switzerland), 10(6), 1-21. https://doi.org/10.3390/app10062 080

Mulawarman, U. 2020. 1. ekonomi dan bisnis 1 .

Nazaruddin, A.O. 2017. Pengaruh Penguatan Kelompok Tani Terhadap Partisipasi dan Motivasi Pemuda Tani Pada Usaha Pertanian di Leuwiliang, Bogor. Jurnal Agribisnis Terpadu: 1-14.

Šimpachová, M. 2018. What Is the Motivation and Barriers for Young People To Enter What Is the Motivation and Barriers for Young People To Enter the Agricultural Sector?, (February).

Widhaningrat, S.K. 2010. Angkatan Kerja. Dasar-Dasar Demografi. 